\title{
PROPAGAÇÃO DA POLUIÇÃo ATMOSFÉRICA POR FLÚOR NAS ÁGUAS SUBTERRÂNEAS E SOLOS DE REGIÕES PRÓXIMAS ÀS INDÚSTRIAS DE FERTILIZANTES (RIO GRANDE, RS)
}

\author{
Nicolai Mirlean*, Maria R. Casartelli e Marina R. D.Garcia \\ Departamento de Geociências, Fundação Universidade Federal do Rio Grande, CP 474, 96201-900 Rio Grande - RS
}

Recebido em 17/10/00; aceito em 30/8/01

\begin{abstract}
PROPAGATION OF AIRBORNE FLUORINE CONTAMINATION ON GROUNDWATER AND SOIL NEAR FERTILIZER FACTORIES IN RIO GRANDE (RS). Fluoride concentration was determined in rainwater, ground water and soil in the zone of fertilizer industry in the city of Rio Grande. In contaminated rainwater fluorine concentration was registered up to the value of $4,4 \mathrm{mg} \cdot \mathrm{L}^{-1}$. Fluorine concentration in the shallow ground water in general reflects its distribution in the atmosphere, but cannot be used as marker of atmosphere contamination in the urban area due to dissolving influence of residential effluents. The $0,01 \%$ $\mathrm{HCl}$ extracts from the set of surface soil samples demonstrates fluoride distribution in the zone of influence of industrial emissions, which coincides to the numerical simulation of fluorides dispersion in the air.
\end{abstract}

Keywords: fertilizer industry; fluorine distribution; environmental pollution.

\section{INTRODUÇÃO}

O flúor é amplamente conhecido como poluidor do meio ambiente e uma das fontes são as fábricas de fertilizantes. A poluição por fluoreto, nas proximidades dessas fábricas, tem sido intensamente estudada nos diferentes meios como: ar, águas, plantas e solos ${ }^{1-5}$. A maioria dessas contribuições aborda os efeitos das emissões industriais sobre o desenvolvimento de plantas terrestres através de biomonitoramentos da qualidade do ar ${ }^{6-11}$, no entanto, não se encontram estudos sobre a distribuição de flúor no solo, fluoreto em águas subterrâneas e nas precipitações atmosféricas com a finalidade de identificar a dispersão deste elemento no ar atmosférico.

No Brasil existem poucos estudos publicados sobre o enriquecimento de flúor em zonas industriais ${ }^{10,12}$; dentre esses se destaca o trabalho de Domingos ${ }^{12}$ que, ao estudar as consequiências da poluição atmosférica na vegetação e no solo da Serra do Mar, região próxima a Cubatão, constatou que grande parte do flúor, ao ser ciclado em quantidades elevadas, permanece imobilizado no solo.

A nossa região de estudo, município de Rio Grande, localizada em zona estuarina da Lagoa dos Patos (RS), próxima à desembocadura no Oceano Atlântico, possui um complexo industrial-portuário onde se destacam as fábricas de fertilizantes, que lançam entre outros resíduos, o flúor nas diferentes formas. Além das emissões deste contaminante pelas chaminés das fábricas, o transporte da matéria prima e do produto também determinam a sua dispersão.

Apesar da elevada contaminação ambiental causada por compostos do flúor nesta região, tanto na área industrial como urbana ${ }^{6}$, com registros de danos graves à vegetação ${ }^{13} \mathrm{e}$ animais - fluorose bovina ${ }^{14}$, por exemplo, não existem estudos precedentes a este sobre os teores e a distribuição de flúor nos diferentes meios. Embora se destaque o estudo de Brigoni ${ }^{6}$ por ter simulado a dispersão dos fluoretos no ar por modelagem matemática através das emissões gasosas industriais.

Estudar a distribuição do flúor diretamente no ar é bastante complexo, principalmente pela dificuldade nos procedimentos de amostragem como: necessidade de distribuir muitos pontos para co-

\footnotetext{
*e-mail: dgeonmir@ super.furg.br
}

leta de amostras de ar e dificuldades de recolher estas no mesmo instante.

Em razão das dificuldades apresentadas, experimenta-se identificar a propagação do flúor na atmosfera a partir de análises de água da chuva, água subterrânea e da camada superficial dos solos, utilizando esses meios como "coletores naturais" do flúor dispersado na atmosfera. Para determinação das concentrações de flúor, como o fluoreto, na água e no solo, foi empregado o método potenciométrico utilizando um eletrodo íon seletivo sensível à fluoreto ${ }^{15}$.

\section{MATERIAL E MÉTODOS}

\section{Amostragem}

Água da chuva

Foram coletadas 124 amostras de água da chuva parceladamente de 38 eventos de chuva, de outubro de 1998 a julho de 1999. As amostras foram recolhidas em um coletor (funil de polipropileno $\phi=17 \mathrm{~cm}$ ) fixado a $6 \mathrm{~m}$ da superfície do solo, em área aberta localizada em zona afastada e ao leste do centro urbano-industrial. $\mathrm{O}$ coletor foi conectado a uma mangueira de silicone com diâmetro interno de $5 \mathrm{~mm}$, que conduzia a água da chuva para um sistema de fracionamento, constituído por três balões volumétricos de $25 \mathrm{ml}$ e conectados entre si por um sistema de mangueiras, cujo sifão transferia a água de um balão para outro na medida em que este se enchia e se fechava pela impulsão de uma bolinha de isopor. $\mathrm{O}$ fechamento hermético de cada balão com a bolinha foi testado antes de cada amostragem. O volume de água coletado nos balões (três parcelas de chuva) correspondia a $1 \mathrm{~mm}$ de precipitação em cada balão. Ao completar o volume do terceiro balão, todo o restante da água era recolhido em um recipiente plástico ( $4^{\mathrm{a}}$ parcela de chuva). Antes de cada amostragem de chuva realizou-se a limpeza em todos os componentes do coletor que consistia em: lavagem com detergente, enxágües com água da torneira e destilada, solução de ácido nítrico (10\%) e por último enxágüe vigoroso com água destilada. Após a secagem de todos os componentes o coletor era remontado para a próxima coleta. O coletor era aberto no início da chuva. As amostras de água da chuva foram filtradas em membrana Millipore $(0,45 \mu \mathrm{m})$. Parte 
desta amostra filtrada foi recolhida em frascos de vidro e mantida resfriada para posterior determinação de flúor. As determinações de flúor foram realizadas no mesmo dia da coleta ou nos dias subseqüentes. Constatou-se que as amostras de água mantidas nestas condições apresentaram o mesmo valor de fluoreto durante um período de até duas semanas.

\section{Água subterrânea}

Quatro amostras de água de lençol freático foram coletadas na área de estudo. Em cada ponto de amostragem perfurou-se o solo com o auxílio de um cano de PVC até encontrar o nível do lençol freático (profundidade que varia entre $35 \mathrm{a} 120 \mathrm{~cm}$ ). A natureza arenosa e pouco compactada do solo da região possibilitou esse tipo de procedimento $^{16}$. A água subterrânea foi extraída com uma bomba a vácuo manual conectada por mangueiras de silicone a um frasco coletor. Foi adaptada uma malha de porosidade de $63 \mu \mathrm{m}$ no frasco coletor para evitar a entrada de areia. No laboratório as amostras de água subterrânea foram filtradas (membranas Millipore $45 \mu \mathrm{m}$ ) e mantidas sob as mesmas condições das amostras de água da chuva.

Solo

No período da primavera de 1999, foram obtidas 23 amostras de solo. Os pontos de amostragem localizavam-se tanto nos limites da área urbano-industrial como nas zonas distantes do perímetro urbano. Para a coleta das amostras selecionou-se locais não alterados por aterros e trânsito de pessoas, animais e veículos. Foram coletados os primeiros centímetros da camada superficial do solo $(0-5 \mathrm{~cm})$ com o auxílio de uma pá. As amostras foram acondicionadas em sacos plásticos e transportadas ao laboratório onde foram secas à temperatura ambiente.

\section{Procedimentos analíticos}

\section{Água da chuva e subterrânea}

Logo após a amostragem e filtragem das amostras, foram realizadas as leituras de $\mathrm{pH}$ e condutividade utilizando-se os métodos e equipamentos padronizados ${ }^{15}$. As análises de fluoreto foram realizadas pelo método potenciométrico, utilizando-se eletrodo para fluoreto modelo 96-09, da Orion de acordo com as especificações do fabricante $^{17}$. A faixa de $\mathrm{pH}$ nas soluções de trabalho do eletrodo encontrase entre 5 e 8 e a mais recomendada para a detecção de fluoreto nas soluções é de 5,0 - 5,5. Para manter o pH nesta faixa empregou-se a solução tampão TISAB - que resulta da mistura de ácido acético com cloreto de sódio titulado com hidróxido de sódio até atingir $\mathrm{pH}$ entre 5,0 e 5,5. Foram utilizadas curvas-padrão para determinar as concentrações de fluoreto, cujos padrões foram preparados com soluções de NaF e TISAB numa mesma proporção (1:1). No preparo das amostras para a análise foi acrescentado TISAB nesta mesma proporção.
Solo

As amostras foram secas à temperatura ambiente e peneiradas na fração menor que $1 \mathrm{~mm}$. A seguir elas foram submetidas a extrações com solução aquosa e extratores químicos. Foram realizados três tipos de extrações químicas, a saber: $\mathrm{HCl}$ 0,01\%; TISAB e Ácido Acético $10 \%$. As concentrações desses extratores ácidos foram adotadas devido o $\mathrm{pH}$ da mistura entre a solução e TISAB permanecer na faixa entre 5,0 e 5,5 que corresponde à otimização do eletrodo íon seletivo sensível a fluoreto. Na extração de fluoreto por solução aquosa, a água destilada foi o extrator. Para todas as extrações foi mantida a mesma proporcionalidade entre a solução e o solo (1:1, em peso). Em cada extração, a mistura de solo e extrator era inicialmente homogeneizada em agitador orbital por 10 min e deixando-os em contato por $20 \mathrm{~h}$. Após esse período as amostras foram novamente agitadas por $10 \mathrm{~min}$ e centrifugadas por $10 \mathrm{~min}$ a $10.000 \mathrm{rpm}$ e suas fases separadas por filtragem em membranas Millipore $(0,45 \mu \mathrm{m})$.

Para leitura de fluoreto nos extratos ácidos de solo empregou-se a solução tampão que resulta da mistura de $\mathrm{HCl}$, TRIS ( $\left.\mathrm{NH}_{2} \mathrm{C}\left(\mathrm{CH}_{2} \mathrm{OH}\right)_{3}\right)$ e tartarato de sódio. Essa solução tampão favorece a complexação de $\mathrm{Fe}^{3+}$ e $\mathrm{Al}^{3+}$ até a concentração de $100 \mathrm{mg} . \mathrm{L}^{-1}$, fazendo com que o flúor permaneça na sua forma iônica durante as análises ${ }^{18,19}$ e nos extratos de solo obtidos pela solução aquosa adotou-se a solução tampão TISAB .

Todos os procedimentos analíticos envolvidos na determinação da concentração de fluoreto nas amostras foram realizados conforme recomendação e critérios preconizados por metodologia padrão $0^{17,} 18$.

O material necessário para os procedimentos de amostragem e estocagem foi lavado com solução de $\mathrm{HNO}_{3}(10 \%)$ e enxagüados vigorosamente com água destilada.

\section{RESULTADOS E DISCUSSÃO}

Os compostos de flúor presentes na atmosfera são diluídos e arrastados, rapidamente, pela água da chuva e por isso a concentração do fluoreto na primeira parcela de chuva representa a contaminação do ar neste ponto de coleta. Na Tabela 1, constata-se que durante a continuidade do evento de chuva, a concentração de fluoreto diminui drasticamente.

Foi observado que as concentrações de fluoreto no ponto de amostragem variam de 0,05 a 4,4 mg. $\mathrm{L}^{-1}$. Nesta região consideramos como nível de background na água da chuva os valores médios de fluoreto $\left(0,08 \pm 0,05 \mathrm{mg} . \mathrm{L}^{-1}\right)$ referentes à quarta parcela da chuva que corresponde aproximadamente a $95 \%$ do volume total das precipitações. Esse valor supera quase duas vezes o valor de background mundial ${ }^{20}$. As concentrações de fluoreto acima de $1,0 \mathrm{mg} . \mathrm{L}^{-1}$ foram encontradas somente quatro vezes na primeira parcela da chuva durante o período de amostragem. Na Figura 1, observa-se que a água referente à primeira parcela da chuva com concentração de fluoreto maior que $1,0 \mathrm{mg} . \mathrm{L}^{-1}$ tem $\mathrm{pH}$ menor que 5,6 e condutividade em uma faixa relativamente baixa $\left(120-170 \mu \mathrm{S}^{-1} \mathrm{~cm}^{-1}\right)$, se forem conside-

Tabela 1. Concentração de fluoreto $\left(m g . L^{-1}\right)$ na água da chuva parcelada

\begin{tabular}{ccccc}
\hline & \multicolumn{4}{c}{ Parcelas da chuva } \\
\hline $\mathrm{n}=38$ & $1^{\mathrm{a}}$ & $2^{\mathrm{a}}$ & $3^{\mathrm{a}}$ & $4^{\mathrm{a}}$ \\
\hline $\mathrm{X} \pm \sigma$ & $0,42 \pm 0,75$ & $0,13 \pm 0,11$ & $0,12 \pm 0,13$ & $0,08 \pm 0,05$ \\
máx-min & $4,40-0,60$ & $0,54-0,06$ & $0,76-0,05$ & $0,29-0,05$ \\
\hline
\end{tabular}

$\mathrm{X}$-média aritmética, $\sigma$ - desvio padrão, $\mathrm{n}$ - número de amostras utilizadas no cálculo. 

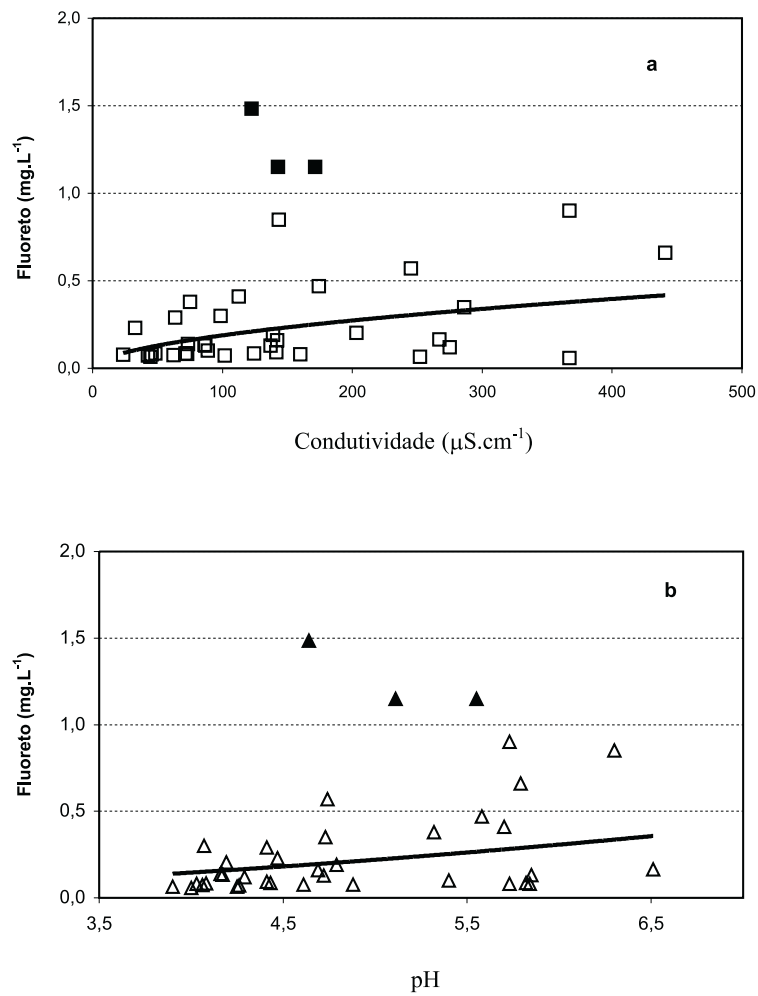

Figura 1. Correlações da concentração de fluoreto na primeira parcela das chuvas com condutividade(a) e pH(b), em 37 amostras ( a amostra com concentração 4,4 mg. $\mathrm{L}^{-1}$, pH 3,93 e condutividade 131,1 $\mu$ S.cm $\mathrm{cm}^{-1}$ não foi representada). Os símbolos preenchidos representam amostras com concentração de fluoreto maior que 1,0 mg. $\mathrm{L}^{-1}$

rados todos os valores de concentração nas primeiras parcelas de água da chuva analisadas.

Para os valores menores que $1,0 \mathrm{mg} . \mathrm{L}^{-1}$ podem ser determinadas algumas relações entre as concentrações de fluoreto com $\mathrm{pH}$ e condutividade da água da chuva (Figura 1). Verifica-se que a concentração de fluoreto até $1,0 \mathrm{mg} . \mathrm{L}^{-1}$ eleva-se com o aumento de $\mathrm{pH}$ e da condutividade.

Poder-se-ia admitir que, tanto a distribuição de flúor como as características apresentadas pelas primeiras parcelas da chuva, deveriam estar relacionadas com a dispersão de sais marinhos ${ }^{21}$. Porém, este argumento não pode ser comprovado, pois as concentrações de flúor encontradas nas águas do mar são próximas de $1,0 \mathrm{mg} \cdot \mathrm{L}^{-1} 22 \mathrm{e}$, para que seus teores atingissem ainda valores de $0,5 \mathrm{mg} . \mathrm{L}^{-1}$, a condutividade da água da chuva deveria apresentar valores muitas vezes maiores do que os obtidos neste estudo.

Na Tabela 2, observa-se que a direção do vento para as chuvas com maior concentração de fluoreto (mais de 1,0 mg.L $\mathrm{L}^{-1}$ ) tem os setores E, NE e SE, que coincidem com a direção entre as fábricas e o ponto de coleta de amostras de água da chuva e, tem geralmente caráter ácido ${ }^{23}$. As chuvas que começam quando o vento está na direção oposta ao das fábricas (W, NW, SW), isto é, originário dos pampas, apresentam teores máximos de fluoreto que não superam $0,5 \mathrm{mg} . \mathrm{L}^{-1}$.

Este estudo da concentração de fluoreto na água da chuva mostra que a poluição da atmosfera por fluoreto propaga-se por grandes extensões (das fábricas até o ponto da coleta a distância é mais de 10 $\mathrm{km}$ ), que a concentração do fluoreto depende da direção do vento no momento que se inicia a chuva e ainda, que as emissões das fábricas são as principais fontes dessa contaminação.

Os solos desta região, pobres em matéria orgânica e argilominerais (solos arenosos distróficos) ${ }^{24}$, favorecem a penetração rápida das precipitações, e como os compostos atmosféricos de flúor são altamente solúveis, o fluoreto deve facilmente atingir o lençol freático. Por conseguinte, imagina-se que a concentração de fluoreto nas águas subterrâneas pode caracterizar o nível de contaminação atmosférica determinado para este elemento. Como o lençol freático encontra-se aproximadamente no mesmo nível, em toda a área de estudo, e não existe variedade significativa na composição dos solos, esperava-se que a concentração de fluoreto na água subterrânea diminuísse em relação direta com o distanciamento das fábricas. Mas esse comportamento esperado não se manifestou claramente. Nas proximidades das fábricas, a concentração do flúor na água subterrânea mostrou valores variáveis e não tão elevados como era esperado. De maneira geral, pode ser observado através dos resultados obtidos que na distância de 2,5 km das fábricas a concentração de fluoreto no lençol freático pode diminuir muito (Tabela 3 ).

Percebe-se que o estudo sobre a distribuição de fluoreto no lençol freático, em zonas urbanas, representa somente uma linha de tendência, isto é, não permite que se estabeleça a forma da zona de dispersão de flúor no ar atmosférico. Esta limitação provavelmente decorre de dois fatores: pela ausência de sistema de canalização de esgotos em grande parte da área urbana os efluentes domésticos penetram no lençol freático, alterando a concentração de fluoreto nas águas subterrâneas; e durante os períodos de estiagem, caracterizados por baixas taxas pluviométricas, o nível do lençol freático dimi-

Tabela 2. Concentrações máximas de fluoreto $\left(\mathrm{mg} . \mathrm{L}^{-1}\right)$ registradas na primeira parcela da água da chuva cujas direções de vento eram dos quadrantes $\mathrm{E}$ e W

\begin{tabular}{cc}
\hline $\begin{array}{c}\text { Direção do vento no momento } \\
\text { do início da chuva }\end{array}$ & $\begin{array}{c}\text { Fluoreto } \\
\left(\mathrm{mg} . \mathrm{L}^{-1}\right)\end{array}$ \\
\hline Leste (E) & 1,48 \\
Nordeste (NE) & 1,15 \\
Sudeste (SE) & 4,40 \\
Oeste (W) & 0,23 \\
Noroeste (NW) & 0,30 \\
Sudoeste (SW) & 0,38 \\
\hline
\end{tabular}

Tabela 3. Concentrações de fluoreto $\left(\mathrm{mg} \cdot \mathrm{L}^{-1}\right)$ nas águas subterrâneas

\begin{tabular}{|c|c|c|c|c|c|}
\hline \multirow{2}{*}{$\begin{array}{c}\text { Ponto de } \\
\text { Amostragem }\end{array}$} & \multirow{2}{*}{$\begin{array}{l}\text { Distância em relação à } \\
\text { fonte de emissão } \\
\text { de flúor }(\mathrm{km})\end{array}$} & \multirow{2}{*}{$\mathrm{pH}$} & \multirow{2}{*}{$\begin{array}{l}\text { Condutividade } \\
\left(\mu \mathrm{S} . \mathrm{cm}^{-1}\right)\end{array}$} & \multicolumn{2}{|c|}{ Fluoreto } \\
\hline & & & & $\begin{array}{c}\text { na água } \\
\text { subterrânea } \\
\left(\mathrm{mg} \cdot \mathrm{L}^{-1}\right)\end{array}$ & $\begin{array}{c}\text { extraível do solo } \\
\text { por } \mathrm{HCl} 0,01 \% \\
(\mathrm{mg} / \mathrm{kg})\end{array}$ \\
\hline 13 & 0,1 & 5,92 & 642 & 1,49 & 7,80 \\
\hline 12 & 0,2 & 4,97 & 309 & 1,77 & 2,38 \\
\hline 19 & 0,5 & 7,86 & 855 & 2,20 & 0,53 \\
\hline 15 & 2,5 & 7,18 & 536 & 0,08 & 0,02 \\
\hline
\end{tabular}


nui e possibilita a invasão de águas da zona estuarina e das lagoas interiores, as quais estão poluídas por flúor, por receberem os lançamentos líquidos das fábricas de fertilizantes (durante o período de estudo registrou-se 5,0 mg. $\mathrm{L}^{-1}$ de fluoreto na água do Saco da Mangueira). Esses dois fatores influenciam tão fortemente na composição da água subterrânea nesta região, que a concentração de fluoreto neste meio não pode ser usada como o refletor da contaminação atmosférica por compostos de flúor.

Tendo em vista os problemas acima referidos para a determinação da dispersão do flúor no meio ambiente através da análise do ar, da água subterrânea e da chuva e também pelos regimes das atividades industriais serem irregulares, determinou-se a distribuição do flúor nas camadas superficiais do solo. Esta abordagem foi adotada com base na metodologia de estudos geoquímicos das zonas urbanas em que se usa a superfície do solo como "coletor natural" dos poluentes nas precipitações atmosféricas ${ }^{22}$.

As extrações com água destilada mostraram a ausência de fluoreto detectável em todas as amostras estudadas. Isto pode significar que parte dos fluoretos dissolvidos são levados para as camadas inferiores do solo, ou o fluoreto forma complexos não solúveis que se fixam no horizonte superficial do solo.

$\mathrm{Na}$ Tabela 4, estão representados os valores de concentração de fluoreto obtidos pelas extrações por $\mathrm{HCl}$, ácído acético e TISAB. Observa-se que, na maioria dos casos, a maior quantidade de flúor foi extraída pela solução de $\mathrm{HCl}$, seguida por TISAB e ácido acético, sendo que esta última extraiu os menores teores para todas as amostras utilizadas como teste.

Tabela 4. Concentrações de fluoreto $\left(\mathrm{mg} \cdot \mathrm{kg}^{-1}\right)$ determinadas nas extrações das amostras da camada superficial de solo (locais de coleta representados na Figura 2)

\begin{tabular}{cccc}
\hline $\begin{array}{c}\text { Amostras } \\
\text { de Solos }\end{array}$ & $\mathrm{HCl} \mathrm{0,01 \%}$ & Tipos de Extrações \\
\hline 1 & 0,042 & 0,120 & 0,001 \\
7 & 2,500 & 0,015 & 0,001 \\
15 & 0,016 & 0,032 & 0,001 \\
16 & 0,146 & 0,070 & 0,007 \\
17 & 0,818 & 0,532 & 0,177 \\
18 & 0,728 & 0,188 & 0,050 \\
21 & 0,342 & 0,060 & 0,004 \\
\hline
\end{tabular}

Não fica, porém, evidenciada uma razão constante entre os teores de flúor extraído pelos diferentes tipos de extratores, pois os resultados obtidos foram bem próximos ou ainda muito afastados (até 100 vezes). Tais diferenças podem ser explicadas pela presença de flúor no solo sob determinada forma que é extraída diferentemente por cada extrator.

Pelos resultados obtidos nas extrações, optou-se pelo método de extração por $\mathrm{HCl} 0,01 \%$, porque essa solução mostrou-se mais eficiente ao extrair maior quantidade de flúor das amostras de solo.

Os teores obtidos na extração de flúor por $\mathrm{HCl}$ estão representados no mapa de isolinhas (Figura 2). Pelo mapa pode-se identificar que as zonas de localização das fábricas de fertilizantes em Rio Grande caracterizam-se pelas concentrações mais significativas de flúor extraído. Essa zona de dispersão de flúor pode variar desde valores mínimos (ponto 23 no mapa) até elevados teores e ocupa uma área total de aproximadamente $200 \mathrm{~km}^{2}$. Também a forma de dispersão deste elemento mostra a influência dos ventos predominantes na distribuição espacial das emissões. Observa-se, então, pelo menos duas vias principais de transporte de flúor das emissões, nordeste: sulsudoeste e noroeste que, em princípio, corresponde à figura das

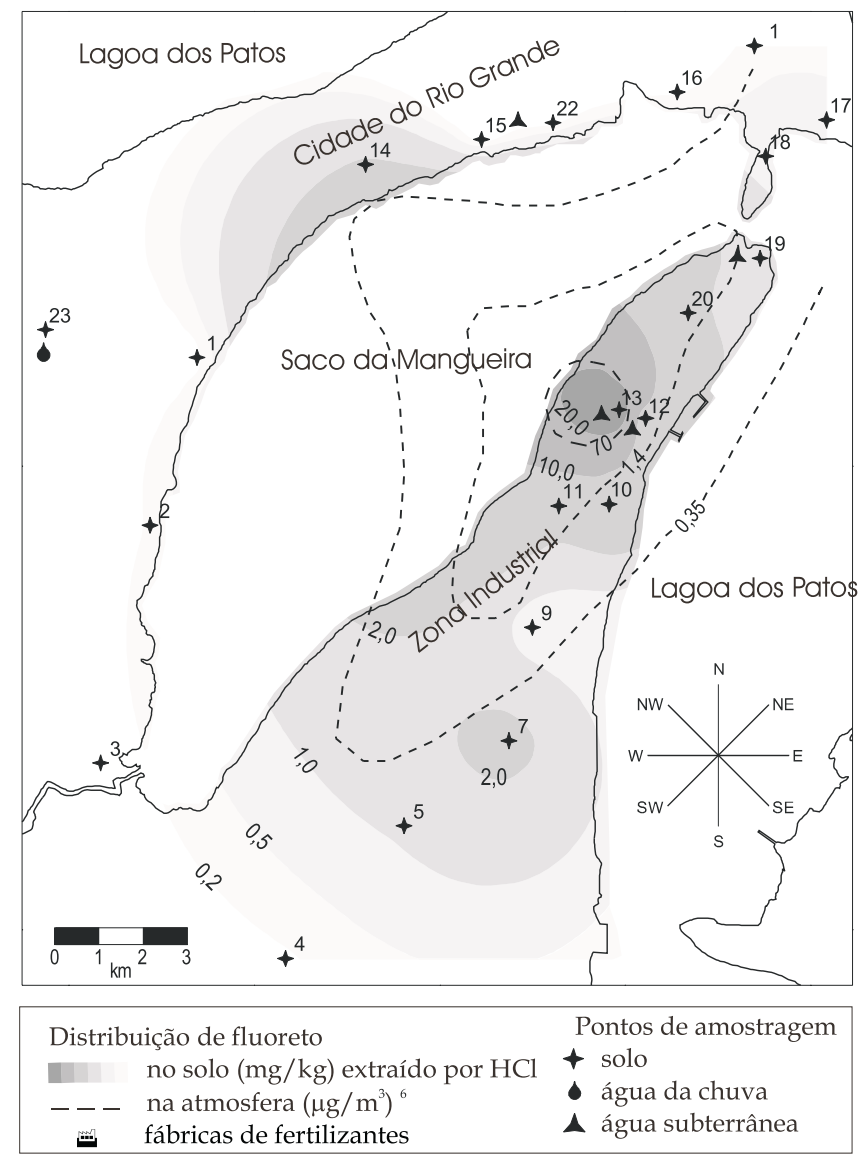

Figura 2. Esquema da distribuição espacial do fluoreto extraível do solo por $\mathrm{HCl}$ 0,01\% e dos fluoretos das emissões das fábricas na atmosfera obtida por modelagem matemática ${ }^{6}$

isopletas do flúor dispersado na forma de fluoretos gasosos das emissões industriais obtida pela modelagem matemática ${ }^{6}$.

A afinidade entre as formas das isopletas do flúor no ar e das isolinhas das concentrações do fluoreto extraído dos solos pode ser explicada pelo caráter complexo das emissões das fábricas. Estas emissões contêm flúor tanto na forma de fluoreto gasoso como na forma de microgotículas e finas partículas sólidas. Esta mistura de compostos de flúor propaga-se pelo afastamento das emissões, submetendo-se aos mesmos fatores de dispersão no ar. Entretanto, a precipitação desses componentes, na superfície da terra, acontece pelos seguintes fatores: os fluoretos gasosos diluem-se na atmosfera até valores de background com o aumento da distância do centro da poluição; e a velocidade de precipitação das partículas sólidas e gotículas depende de seus tamanhos e pesos específicos. Estes fatores ocasionam uma anomalia pontual na superfície do solo que, por sua zonalidade, corresponde à intensidade da contaminação do ar por um elemento. Desta mesma maneira, as zonas de contaminação máxima do ar por gases poluentes são determinadas pela contaminação dos solos por metais pesados nas proximidades das fábricas de siderurgia e usinas termoelétricas movidas a carvão ${ }^{25}$.

\section{CONCLUSÕES}

As emissões das fábricas de fertilizantes enriquecem a atmosfera com fluoreto dissolvido na água da chuva. A concentração de fluoreto na água da chuva no ponto de coleta depende, entre outros fatores, da direção do vento. Ainda nos locais mais afastados das 
fábricas, as concentrações de flúor na água da chuva podem atingir valores que superam muitas vezes o teor de background. A lixiviação de fluoreto pelas chuvas provoca o aumento dos seus teores na água subterrânea e, de modo geral, determina que a sua concentração se relaciona com a distância das fontes de poluição, e talvez, pela influência das emissões de esgotos domésticos e invasão das águas do sistema estuarino, essas concentrações não apresentam uma distribuição de maneira gradiente da contaminação por fluoreto.

Dos quatro tipos de extração (água destilada, TISAB, ácido acético $10 \%$ e $\mathrm{HCl} \mathrm{0,01 \% )} \mathrm{de} \mathrm{fluoreto} \mathrm{do} \mathrm{solo,} \mathrm{a} \mathrm{extração} \mathrm{por} \mathrm{HCl}$ mostrou a maior quantidade de fluoreto extraído para a maioria dos casos estudados. A forma das isolinhas da concentração do fluoreto, extraído dos solos por $\mathrm{HCl}$, em princípio, corresponde à figura das isopletas do elemento disperso sob a forma gasosa pelas emissões industriais obtida pela modelagem matemática. A presença da afinidade entre estas distribuições permite propor o estudo da distribuição de flúor extraível por $\mathrm{HCl}$ 0,01 \% da camada superficial do solo e a análise potenciométrica do fluoreto como método de avaliação da propagação da contaminação do ar, por compostos de flúor, emitidos pelas fábricas de fertilizantes.

\section{AGRADECIMENTOS}

Os autores agradecem ao programa de Apoio ao Desenvolvimento Científico e Tecnológico -PADCT/PIBIC - CNPq pelas bolsas concedidas.

\section{REFERÊNCIAS}

1. Rippel, A.; Fluor. Off. Quart. J. Intern. Soc. Fluor. Res. 1970, 3, 18

2. Sidhu, S.S.; Air Pollut. Control Assoc. J. 1980, 29, 1069.

3. Abudhaise, B.A. ; Abuomar, N.I.; Fluoride 1998, 31, 137.
4. Meeussen, J.C.L.; Scheidegger, A.; Hiemstra, T.; VanRiemsdijk, W.H.; Borkovec, M.V.; Environ. Sci. Technol. 1996, 30, 481.

5. Klumpp, A.; Domingos, M.; Klumpp, G.; Sci. Total Environ. 1996, 192, 219.

6. Brigoni, S.F.; Rel. Inter., Dept ${ }^{\circ}$. Meio Ambiente, Div. Controle Qual. Ar. Porto Alegre, 1983, 26.

7. Mccune, D.C.; Lauver, T.L.; Hansen, K.S.; Can. J. Forest Res. - Revue Can. Rech. Forestiere 1991, 21, 756.

8. Horntvedt, R.; Eur. J. Forest Pathol. Blackwell Wissenschafts-Verlag GMBH, Berlin, 1997, 27, 73.

9. Ando, M.; Tadano, M.; Asanuma, S.; Tamura, K.; Matsushima, S.; Watanabe, T.; Kondo, T.; Sakurai, S.; Ji, R.; Liang, C.; Cao, S.; Fluoride: Environ. Fluor. Pollut. 1998, 31, 129.

10. Silva, M.D; Domingos, F.; Klumpp, G.; Klumpp, A; Poggiani, F.; III Simp. Ecossis. da Costa Bras. 1993, 2,150.

11. Chen, C.; Xia, Y.; Lin, M. ; Jiangki, Y.C.; Fluoride: Environ. Fluor. Pollut. 1998, 31,129.

12. Domingos, M.; Lopes, M.I.M.S.; Vuono,Y.S.; Klumpp, A.; Gudrvan, G.; Lress, R.; Mayer, R.; III Simp. Ecossis. da Costa Bras. 1993, 2,10.

13. Nunes. L.A.L.; Rel. Inter., Dept ${ }^{\circ}$. Meio Ambiente, Gerência da Qualidade do Solo, Porto Alegre, 1978, 32.

14. Riet-Corrêa, F.; Oliveira, J.A.; Méndez, M.C.; Schild, A.L.; Pesq. Vet. Bras. $1983,3,107$.

15. Vogel, A.I. Em Analítica Química Quantitativa; 5 aed., LTC: Rio de Janeiro, 1992, p. 690

16. Lemos, R.C.; Santos, R.D.; Manual de Descrição e coleta de solo no campo; Soc. Bras. de Cienc. do Solo: Paraná, 1996, p. 84.

17. ORION - Orion Research Incorporated; Instruction Manual; 1991, p. 37.

18. Arnesen, A.K.M.; Water, Air, Soil Pollut. 1998, 103, 375.

19. Rai, K.; Agarwal, M.; Srivastava, S.; Kumari, K.M.; XXI nd Conf. Intern. Soc. for Fluor. Res. 1998.

20. Beus A.A.; Environ. Geochem. Nedra, Moscow, 1979, p. 247

21. Drever,J.I.; The Geochemistry of Natural Waters; Prentice-Hall, Inc.: NJ, 1982, p. 388.

22. Perelman A.I.; Geochemistry; Vysh.School: Moscow, 1989, p. 527

23. Mirlean, N; Vanz, A.; Baisch, P.; Quim. Nova 2000, 23, 590.

24. Cunha, N.G.; Silveira, R.J.C.; Geomorfología e Solos de Rio Grande; CPACT-EMBRAPA: Pelotas, 1995, p. 112.

25. Saet Yu, E.; Environmental Geochemistry, Nedra: Moscow, 1991, p. 356. 